\title{
DO WE REALLY NEED COMPUTERS IN CLASSROOM INSTRUCTIONS
}

\author{
Harpreet Kaur \\ Assitant Professor, . \\ M.L.M. Institute of Education, Mudhal, Verka, Amritsar
}

\begin{abstract}
The Quality of education depends to a great extent on the quality of teachers. It is a known fact that quality teachers opt for an innovation in their teaching aspect through integrating technology in the classroom instruction to give the best to students. Since technology is a powerful tool for problem solving, conceptual development and critical thinking help to make the learning process much easier for the students. To be effective in the classroom instruction, teachers should acquire the knowledge and skills to use the new challenges in promoting innovative teaching strategies that are studentcentered, collaborative, engaging, authentic, self-directed and based on the development of higher order thinking skills with respect to handling classes for students which aim to achieve high academic standards.

Today learning is approached as a constructive, self-regulated, and cooperative to meet the individual difference and technology-oriented process. In these approaches a strong emphasis is placed on the learner as an active agent in the knowledge acquisition process. This view on learning and instruction is in contrast with the 'Objectivistic' viewpoint in which information provided by, for example, a teacher is more or less directly transferred to the learner. In the constructive viewpoint, the teacher plays a more facilitative role, supporting learners in a self-directed, constructive learning process. Developments in the objectivistic tradition were encouraged by the availability of computer-based learning environments that were in line with this approach, such as programmed instruction, tutorials, drill-and-practice programs. Also within the constructivist approach we find computer-learning environments that help to advance developments.
\end{abstract}

\section{General Terms}

Computer, Education, Instructions, Learning, Motivation.

\section{Keywords}

Computer, Education, Instructions, Learning, Motivation.

\section{INTRODUCTION}

New technology almost always addresses the changing paradigms of education and training. It changes the way the teacher teaches and students do their work.

It provides them new tools to increase the productivity in terms of learning outcomes. It makes learning easier, more effective and more enjoyable. In brief, technology provides following benefits:-

1) Facilitating Student's Achievement: - Research has shown that computers can assist in improving students' achievement. This includes achievement in several different areas. For example, student's motivation is increase when we use technology to assist a teacher in facilitating a particular lesson. In addition, if we use technology in the classroom it helps to prepare students for the outside world. Finally, technology can offer resources and experiences that books are not able to offer.

\section{a)Enhancing Students' Motivation}

Motivation is an important variable in education. When learner is motivated, the effect of learning is enhanced. For example, it is more interesting to fly a simulated Airplane than it is to read about flying it. It provided dynamic, realistic situations that motivate learner to engage in active learning. Students are found to be challenged, engaged, and more independent when using technology.

\section{b) Enhancing Students' Achievement}

Using technology in the classroom, specifically computerassisted instruction, can help students achieve success in the classroom provided the teacher knows how to use the computers effectively. Often times teachers express their concerns that they do not have the time to devote to students who need individualized instruction. Whether it is gifted students or students who may need extra assistance. Computers allow for individualized extra attention, attention that the teacher may not be able to provide during regular classroom hours. Computers can also help improve student performance overall in the classroom in that they can provide students with immediate feedback “...instant feedback motivates them (students) to continue. In a decade-long series of studies, students in classes that use CAI outperformed their peers on standardized tests of basic skill achievement by 30 percent on average.

\section{c) Preparing students for the outside world}

In order to be successful in today's job market one must be proficient in the use of technology, specifically computers. This means that any student who does not know the essential of using computer - word processors, spreadsheets, operating system - will be at a distinct disadvantage. It is our job as educators to prepare our students so that will be marketable in today's job market. In order that an individual is marketable, they have to have some experience in using computers; they may be turned down for a job. Some schools have also reported that by incorporating a technology rich curriculum into their schools, they are seeing at risks students stay in school. "The reason is that if a student sees that by staying in school they will gain practical experiences that can be used in everyday life, than it is worth staying in school.

\section{d) Lessons Can Be More Interesting and Hands On experience}

One of the questions that were raised at the beginning of this course is if computer assisted instruction (or CAI) is truly more beneficial than a blackboard or overhead projector. Although it is true that for certain lessons it is just as easy to use the age old blackboard and text books; computers can still over many benefits that "normal" classroom instruction cannot. For example, if your class is studying something such as biology, a textbook cannot show the same illustration such of something such as a heart that a computer can. A computer 
could show three dimensional, as well as more realistic illustrations of such things as a heart or the anatomy of an animal. A student is much more likely to remember the image of the anatomy of a frog using a computer versus a textbook.

\section{Transfer of learning}

The second benifit of computer- based instructional is transfer of learning.Computer based instructional has a good transfer of learning because what is learned in a computer based instuctional result in improved performance in the real situtation, where as a book only provide information and hints on how to do something.

\section{Authentic learning}

The third benefit of computer based instructional is that it provides an authentic learning environment. Current learning theories usually dictate that in the learning process, learners should be actively involved in constructing or reconstructing their knowledge bases. The best way to learn how to do something is to do it . It is something not practical or realistic to allow learners to be able to practice every skill in real life . This method of learning is effective because people learn to act by acting ; they learn to live by living ; they learn to do by doing and they learn to understand there spirits when they reflect on their interactive activity.

\section{4.hysically Safe Learning Environment}

The fourth benefit of computer based instructional is provisions of a physically safe learning environment. If a learning objective is to operate a nuclear power plant, for a safety reason it is not appropriate to use a real plant .On the other hand, in computer based instructional learners can practice under safe, non-threatening circumstances .

\section{Cost saving}

The fifth benefit of computer based instructional is cost saving that may be realized through reduced operation of real systems, as in the case of flight simulation. Some practical equipment may not be available or may be too expensive to allow a number of learners to learn by doing. The cost of an aircraft simulation mimics the actions and feels of a real aircraft is very much high. Computer based instructional has aided the situation by providing a more cost effective platform for delivering a simulated environment. For ethical, safety or cost benefit reasons, allowing learners the opportunity to learn directly in real environments may be undesirable and something even impossible.

\section{PROBLEM DEFINTION}

The objective of this paper is to provide educators with an opportunity to see the benefits of using technology in the classroom. I believe that the benefits of using technology far outweigh the negative aspects of using technology, and will demonstrate this in my paper. This paper will also will address some of the challenges teachers face in using technology in their classrooms, as well as offer some solutions to these challenges.

\section{IMPACT ON TEACHERS AND TEACHING METHODOLOGY}

Using Computer in the classroom instruction, teacher would have enormous positive impact on different aspects which are listed below:-
* Teachers using Technology can plan and prepare lessons more efficiently and more effectively.

* Teachers become multi-facilitators.

* It helps to promote interdisciplinary approach.

* Teaching-learning enterprises becomes more resultoriented

* Helps the teachers in guiding the student's needs and explore in the learning process.

* Develop effective teaching tools and designing of the modules.

All the above aspects would help in teaching the content and enrich their teaching profession.

\section{CHALLENGES}

Technology in the schools effectively used helps students to "organize complex information, recognize patterns, draw inferences, and communicate findings." They also "exhibit superior organizational and problem solving skills." Obviously, the move to bring technology to the classroom is a great benefit. Yet little attention and fewer funds have been invested on the real catalyst for learning the teacher. Many can recount the disappointing stories of computer still in their boxes or sitting at the back of the room with their plastic cover over them because teacher don't know how to use them. However, in many cases ,the training offered is traditional, stand -up training which has some obvious drawbacks:-

\section{1) Professional Development for Teachers:}

Professional Development for Teachers, or lack thereof, is probably the largest obstacle facing teachers in using technology in their classrooms. Few schools at this point do not have access to computers, so the problem is not that there is a lack of technology. The problem is that teachers do not know how to use the technology provided. Teachers voice their frustrations with not having the time, and or funding to receive knowledge on how to use technology in their classrooms.

"Teachers...must become "fearless in their use of technology" and empowered by the many opportunities it offers. Most teachers want to learn to use educational technology effectively, but they lack the time, access, and support necessary to do so.

\section{a) Providing Professional Development on an Ongoing Basis}

In a research report offered by the North Central Regional Educational Laboratory, it points out that sending teachers to a one-day workshop is not sufficient. A one-day workshop will not keep teachers up to date on all of the ways in which we can use technology in our classrooms. In order that professional development be a success, teachers have to be exposed to training frequently. The research also indicates that a "well-planned, ongoing professional development program that is tied to the school's curriculum goals, designed with built-in evaluation, and sustained by adequate financial and staff support is essential if teachers are to use technology appropriately to promote learning for all students in the classroom".

b) Teachers Must Receive Support in Using the Training They Receive 
The technology plan committee has several responsibilities, one of which is to ensure that professional development takes place on an ongoing basis. They are also there to "ensures that all stakeholders support the integration of technology into the curriculum as well as sustained professional development in technology use for all teachers and administrators. The technology planning team ensures that the professional development component of the technology plan is research based and meets high standards for effective staff development

\section{CONCLUSIONS}

Transition, Transformation and Revolution is the scenario of today's educational system. All the processes of learning are crossing the boundaries and barriers. This tendency requires a change in knowledge competencies and skills to deal with technological advancement in networking which is necessary to establish a network between student, educators, parents, institutions and libraries the world over. Therefore, the practice of learning from the utilization of technologies will emerge as Problem-Solving, Guided Instruction, Drill and Practice with Analytical Thinking which includes selfmanagement in a networked environment that can be accomplished in the latest development especially In the knowledge-based society through global networking. So the teachers have to realize that if the students are to achieve a high level of competency and competitiveness, they have no other choice, but to adopt technology as an integrated tool in the field of education.

However, the bottom line is that in order for schools to see the benefits of technology we have to have teachers who are properly trained to use computers in our classrooms. For these benefits to be realized, schools have to support their teachers in getting them trained consistently and constantly on the best ways to use computers in their classrooms. So in the end, the question might not be do we need computers in the classroom, but rather how do we get the best use of the computers?

\section{ACKNOWLEDGEMENT}

Author is highly grateful to her family specially to her husband S. Jaswinder Singh for time to time support.

\section{REFERENCES}

[1] Anandan, K(1997) Potentiality of Internet in Education, Experiments in Education, Vol. XXX, No.6, June 1997, pp.136-139.

[2] Anandan, K.(1997). Multimedia Computer in Education. The New Frontier Education, Vol. XXVII, No. 3, July, September, 1997.

[3] Ballie,C. and Percoco G.(2000). A Study of Present Use and Usefulness of Computer -Based Learning at a Technological University. European Journal of Engineering Education. 25,33-43.

[4] Boyd, A. and Jackson, M.(2004) An Effective Model for Rapid Skills Acquisition through a Simulation-Based Integrated Learning Environment Educational Computing Research. 30,1-21.

[5] Mangan,R.(2003) Teaching Surgery without a Patient Chronicle of Higher Education.46 49-53.

[6] Turkle.S.(2004) How computers Change the Way the Think.Chronicle of Higher Education. 50,26-28.

[7] West, R, and Graham, C.R.(2005) Five Powerful Ways Technology can Enhance Teaching and Learning in Higher Education. Educational Technology.45(3),20-27.

[8] Govindarajan,K.(2010). The Impact of ICT of the capacity building of Teachers and Learners. Proceedings in International Conference on e-Resources in Higher Educational Issues, developments, Opportunities and Challenges pp. 325-327.

[9] www.teachersteachingteachers.org

[10] www.ed.gov/Technology/Plan/NatTechPlan/benfits.html 